\title{
Assessing the current state of supply chain volatility: development of a benchmarking instrument
}

\author{
Benjamin Nitsche ${ }^{\text {a* }}$ (D), Frank Straube ${ }^{\mathrm{a}}$ (D), Peter Verhoeven ${ }^{\mathrm{a}}$ \\ ${ }^{a}$ Technische Universität Berlin, Berlin, Germany \\ *nitsche@logistik.tu-berlin.de
}

\begin{abstract}
Paper aims: The study proposes a benchmarking instrument that enables managers to critically assess the volatility management performance of a product's supply chain to identify areas on which to focus when managing supply chain volatility (SCV).
\end{abstract}

Originality: To the best of the authors' knowledge, the paper is the first to develop an instrument to assess the current state of SCV management of a product's supply chain.

Research method: The benchmarking instrument is based on volatility performance data from 87 manufacturing firms. Additionally, a confirmatory case study in the automotive industry is performed to demonstrate the applicability of the instrument.

Main findings: An industry benchmark is conducted that provides valuable information for practitioners about the current state of volatility management performance in the manufacturing sector. This is of high importance since performance data generated by the focal firm itself are more valuable if they can be put into context with the performance data of competitors.

Implications for theory and practice: Since SCV can originate from multiple sources, a case-based evaluation of of SCV of a product's supply chain is necessary. By applying the instrument, managers will be enables to initiate purposeful strategies that focus on the most pressing sources of SCV.

Keywords

Supply chain volatility. Benchmarking. Performance assessment. Automotive industry.

How to cite this article: Nitsche, B., Straube, F., \& Verhoeven, P. (2019). Assessing the current state of supply chain volatility: development of a benchmarking instrument. Production, 29, e20190022. https://doi.org/10.1590/0103-6513.20190022.

Received: Mar. 26, 2019; Accepted: Aug. 26, 2019.

\section{Introduction}

Managing supply chain volatility (SCV) is one of the core challenges of modern supply chains (SCs) (Christopher \& Holweg, 2011, 2017; Handfield et al., 2013; Wieland et al., 2016). Since volatility has been a challenge across several decades, researchers have, on the one hand, focused on describing the multidimensional sources of SCV and, on the other, developed management strategies for dealing with it. However, to efficiently manage volatility, SC managers need to assess the impact of those SCV sources on their particular SC first, before initiating management strategies (Nitsche, 2018).

In general, to continually manage unintended changes in material flows in a SC, managers need to regularly identify and understand the root cause, assess the impact on the SC, implement mitigation strategies, monitor changes, and learn from experience (Zsidisin et al., 2005). This supply chain business continuity planning process, originally proposed by Zsidisin et al. (2005), is widely accepted in the SC risk management literature, motivating researchers not only to identify strategies for dealing with risks, but also to develop different instruments to assess the specificity of risks to a SC (Aven, 2016). 
Nevertheless, research on the assessment of SCV is sparse. Christopher \& Holweg $(2011,2017)$ were the first to develop a SCV index that assesses the state of SCV from a macroeconomic point of view. However, a case-based evaluation of the current state of volatility of a product's supply chain, taking a microeconomic, focal firm point of view, is still lacking. If implemented, it could assist managers in implementing more target-oriented SCV management.

Based on this, the present study aims to develop an assessment instrument that enables SC managers to critically evaluate the current state of volatility of their products' SCs and identify concrete needs for action. The assessment is performed in such a way as to incorporate a means of benchmarking, not only to provide managers with an assessment of their SCV management performance, but also to show them how they perform against their competitors. Consequently, this study aims to satisfy the following research objectives (RO):

R01: Identify appropriate measures to assess the state of SCV of a product's SC;

R02: Propose a benchmarking instrument that assesses the state of SCV of a product's SC and benchmarks it against competitors;

R03: Analyze the current state of SCV management.

To achieve this, the following section will provide theoretical background on benchmarking/performance measurement of SCs in general and on the concept of SCV. Next, the SCV assessment model is developed and presented. Based on that, the current state of SCV in the manufacturing industry will be analyzed and further contextualized based on a large-scale survey among 87 manufacturing firms aiming to propose industry benchmarks for the assessment model.

\section{Theoretical background}

\subsection{Benchmarking as a tool to assess performance of supply chains}

In general, benchmarking is understood as an approach that involves comparing the performance of own activities in a certain field to those of others, with the aim of achieving superior performance (Camp, 1989). The process of benchmarking has to be repeated on a regular basis with the aim of continuously improving performance in order to stay competitive (Dattakumar \& Jagadeesh, 2003). Benchmarking is also a commonly used tool in SCM because SC managers first need to measure performance in order to identify problems (Peng Wong \& Yew Wong, 2008; Shafiee et al., 2014).

Because of the practical relevance of this approach, SCM researchers have developed numerous benchmarking tools. Some of them aim at assessing the performance of SCM in general (e.g., Shafiee et al., 2014; Stewart, 1995; Supply Chain Council, 2008), but there are also benchmarking models that specifically aim at measuring the performance in dedicated areas such as SC visibility (Caridi et al., 2010), SC collaboration (Simatupang \& Sridharan, 2004), green initiatives (Sangwan \& Choudhary, 2018), carbon emissions (Acquaye et al., 2014), and others. An SC is understood as a complex system of interacting organizations, thus, although benchmarking started on an intra-organizational level, it has been expanded to an inter-organizational level incorporating other stakeholders (e.g., customers; suppliers) in the benchmarking process (Peng Wong \& Yew Wong, 2008).

Due to the variety of SC performance evaluation models, Estampe et al. (2013) developed a taxonomy to characterize SC performance evaluation models based on the decision level affected (strategic, tactical, operational); type of flows analyzed (physical, informational, financial); level of supply chain maturity (intra-organizational, inter-organizational, extended inter-organizational, societal); type of benchmarking (internal, external); contextualization; quality factors; human capital; and sustainability. This taxonomy will be used to characterize the SCV assessment tool developed here.

However, in order to establish a benchmark, appropriate qualitative and/or quantitative performance measures have to be defined that characterize the focus of the benchmark (Beamon, 1999; Chan, 2003). Although research on how to measure and benchmark SC performance exists (e.g. Gunasekaran et al., 2001), to the best of the authors knowledge, specific research on on how to measure and benchmark the performance of SCV management of a manufacturing firm is known. Therefore, the next section provides an introduction to and conceptualization of SCV to better derive suitable measures for assessing SCV. 


\subsection{Conceptualization of supply chain volatility}

Although research on volatility in SCs has been described as one of the most important tasks of SCM research today (Wieland et al., 2016), SCV is not a novel phenomenon. Indeed, research on SCV started with the discovery of the Forrester Effect (Forrester, 1958), later known as the Bullwhip Effect (BWE) (Lee et al., 1997), which initiated a wide-ranging discussion on how to handle volatile material flows in a SC. However, the Bullwhip Effect does not explain the origin of SCV in full (Kim \& Springer, 2008; Nitsche \& Durach, 2018). Numerous researchers have investigated different sources of volatility, such as unpredictable changes in demand, variable lead times, insufficient quality of supplied materials, highly innovative markets, and others.

Nitsche \& Durach (2018) were the first researchers to attempt to synthesize this research on sources of volatility in a study that combined a large-scale literature review with practitioner insights to propose a novel conceptualization of SCV that forms the basis of this research. According to the authors, SCV is caused by 20 different sources that contribute to five distinct dimensions of SCV: organizational, vertical, behavioral, market-related and institutional and environmental volatility.

First, organizational volatility includes that part of SCV that is induced by the focal firm itself (e.g., due to intra-organizational misalignment, inaccurate forecasting, or self-induced price variations). Second, vertical volatility is induced by sources appearing endogenous, including SC partners (e.g., long lead times, supply variability, missing SC visibility). Third, behavioral volatility is understood as the part of SCV that is induced by certain behavioral patterns of individuals in the SC that cause unintended volatile material flows along the SC. More precisely, behavioral volatility is caused by two sources: erratic behavior of decision makers in the SC (e.g., order batching or readjustment of plans) and erratic behavior of customers (e.g., short-term demand changes). Fourth, market-related volatility is induced by the market the focal firm is positioned in (e.g., highly innovative products, high level of competition, seasonality). Fifth, institutional and environmental volatility is induced by sources appearing exogenous to the SC (e.g., national economic and financial instability, political and legal instability) that are most likely very hard for the focal firm itself to control (Nitsche \& Durach, 2018).

Based on this conceptualization, (Nitsche, 2018) subsequently assessed the impact of those sources and dimensions on SCV, although excluding the fifth dimension due to its high context dependency. Consequently, it was proposed that intra-organizational misalignment, inaccurate forecasting, long lead times, erratic behavior of decision makers in the SC, erratic behavior of customers and high level of competition are the six most impactful sources of SCV.

\section{Development of a benchmarking instrument to assess Supply Chain Volatility}

\subsection{Introduction to the benchmarking instrument}

In order to set the conceptual constraints of this study and the developed instrument, we first apply the taxonomy of Estampe et al. (2013), developed to guide SC managers who require an instrument to assess the state of SCV in their products' SCs. The decision level affected is strategic as well as tactical, since the benchmarking instrument seeks to assist managers in critically assessing their SC structures and adjusting them in the medium and long term. The types of flow investigated are mainly physical, because SCV results in a mismatch of supply and demand side material flows at the focal firm (Nitsche \& Durach, 2018), but informational flows are also affected and investigated. Although the developed instrument assesses SCV of a product's SC at the focal firm, the level of SC maturity has to be understood as inter-organizational since it includes data directly connected to suppliers and also customers. The type of benchmarking is external because the user of the benchmarking instrument will benchmark the volatility of its product's SC against the performance of other manufacturers according to different dimensions of SCV. With regard to the contextualization of the developed instrument, it should be noted that it has been developed specifically for use in manufacturing companies. Quality management aspects and human resource management, as well as sustainability initiatives, are outside the scope of the benchmarking instrument (Estampe et al., 2013).

\subsection{Measures to assess supply chain volatility}

In order to assess the level of volatility of a product's SC, it was first necessary to define appropriate measures. Therefore, the study builds upon the conceptualization of Nitsche \& Durach (2018) with the aim of assessing the state of volatility for the first four dimensions of SCV. The fifth dimension of SCV - institutional and environmental volatility - was excluded from the benchmarking instrument due to its high context dependency, 
as argued by Nitsche (2018). Moreover, to make the practical application of the instrument more feasible, we decided to limit the number of variables for each dimension. Therefore, the measurement of each dimension focuses on the most pressing sources of volatility in the respective dimension, as proposed by Nitsche (2018). Development of the model followed an iterative process. In a first stage, possible variables have been identified as suitable for measuring certain sources of SCV by the authors based on previous workshops and in-depth discussions on that project. In a second stage, those measures were refined and prioritized incorporating feedback of two additional SCM researchers. Subsequently, feedback of one additional practitioner was incorporated (that had not been involved in the research process so far) to come to the final set of variables necessary for the benchmarking instrument. All variables for the benchmarking instrument will be further described in the following sub-sections.

\subsubsection{Organizational volatility}

Organizational volatility is mainly caused by intra-organizational misalignment and inaccurate forecasting (Nitsche, 2018). Based on a survey among 88 manufacturing companies, Wagner et al. (2014) investigated how companies can align their organization by means of sales and operations planning (S\&OP). Building on this, they proposed an S\&OP maturity model that outlines the different areas of intra-organizational alignment as well as the embodiment of each maturity level. Based on that, in the proposed benchmarking instrument, intra-organizational misalignment will be measured qualitatively via six distinct characteristics of organizational alignment (formality of the planning process, promotions planning integration, information availability and exchange, planning efficiency, assignment of roles and responsibilities, and integration of planning systems) using the proposed maturity level descriptions of Wagner et al. (2014), as shown in Table 1. The rating of

Table 1. Variables to assess organizational volatility.

\begin{tabular}{|c|c|c|c|}
\hline & $\begin{array}{c}\text { Variable } \\
\text { name }\end{array}$ & $\begin{array}{l}\text { Type of } \\
\text { variable }\end{array}$ & Description \\
\hline \multirow{6}{*}{ 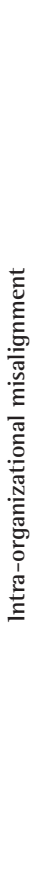 } & $\mathrm{OA}_{1}$ & $\mathrm{Z}[1 ; 7]$ & $\begin{array}{l}\text { level of planning process formality } \\
\text { 1: no formalized planning process } \\
\text { 4: moderately formalized planning process } \\
\text { 7: internally completely formalized planning process }\end{array}$ \\
\hline & $\mathrm{OA}_{2}$ & $\mathrm{Z}[1 ; 7]$ & $\begin{array}{l}\text { level of promotions planning integration } \\
\text { 1: no promotions and price changes planned } \\
\text { 4: issues like promotions and price changes are planned and considered but insufficiently performed } \\
\text { 7: issues like promotions and price changes are planned and considered sufficiently throughout the whole } \\
\text { organization }\end{array}$ \\
\hline & $\mathrm{OA}_{3}$ & $\mathrm{Z}[1 ; 7]$ & $\begin{array}{l}\text { efficiency of information availability and exchange } \\
\text { 1: Information is only partially available including many redundancies } \\
\text { 4: partially centralized information storage; moderate friction losses in information flows } \\
\text { 7: people receive only information they actually need; no friction losses in cross-departmental information flows }\end{array}$ \\
\hline & $\mathrm{OA}_{4}$ & $\mathrm{Z}[1 ; 7]$ & $\begin{array}{l}\text { level of planning efficiency } \\
\text { 1: no alignment of plans throughout the company } \\
\text { 4: due to rudimentary alignment of plans, frequent re-planning is required } \\
\text { 7: due to sufficient alignment of plans, re-planning becomes very rare }\end{array}$ \\
\hline & $\mathrm{OA}_{5}$ & $\mathrm{Z}[1 ; 7]$ & $\begin{array}{l}\text { level of assignment of roles and responsibilities } \\
\text { 1: no concrete assignment of roles and responsibilities with regards to planning tasks and activities } \\
\text { 4: roles and responsibilities are clearly defined but not yet successfully implemented; no dedicated planning } \\
\text { process owner; people partially held accountable for their plans and performance } \\
\text { 7: dedicated planning organization responsible for planning process owner and role descriptions; planning } \\
\text { organization entirely aligned with the business }\end{array}$ \\
\hline & $\mathrm{OA}_{6}$ & $\mathrm{Z}[1 ; 7]$ & $\begin{array}{l}\text { level of integration of planning systems of different business functions } \\
\text { 1: heterogeneous spreadsheets existent and in use } \\
\text { 4: information from other systems need to be manually entered or uploaded (no interfaces) } \\
\text { 7: one integrated system with one single version of truth }\end{array}$ \\
\hline \multirow{6}{*}{ 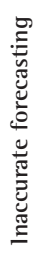 } & MAPE1f & $\mathrm{R}[0 ; 1]$ & 1-month-ahead MAPE (family level) \\
\hline & MAPE3f & $\mathrm{R}[0 ; 1]$ & 3-month-ahead MAPE (family level) \\
\hline & MAPE6f & $\mathrm{R}[0 ; 1]$ & 6-month-ahead MAPE (family level) \\
\hline & MAPE1v & $\mathrm{R}[0 ; 1]$ & 1-month-ahead MAPE (product variant level) \\
\hline & MAPE3v & $\mathrm{R}[0 ; 1]$ & 3-month-ahead MAPE (product variant level) \\
\hline & MAPE6 $_{v}$ & $\mathrm{R}[0 ; 1]$ & 6-month-ahead MAPE (product variant level) \\
\hline
\end{tabular}


those maturity levels is performed, via a self-assessment by the user of the benchmarking instrument, on a scale from 1 (low maturity level) to 7 (high maturity level). Descriptions for maturity levels 1, 4 and 7 are given (see Table 1), but the user is also free to choose intermediate maturity levels. It has to be stated that, for all qualitative variables of the benchmarking instrument, it is recommended that different perspectives from different relevant departments of the manufacturer are included in this self-assessment process.

In general, there are multiple measures to assess the accuracy of a forecast in SCM (Hyndman \& Koehler, 2006; Kerkkänen et al., 2009). One of the more commonly proposed measures is the mean absolute percentage error (MAPE) (Bowerman et al., 2005; Mentzer \& Moon, 2005). This is also often used by practitioners and, in addition, was considered appropriate by other benchmarking studies (Weller \& Crone, 2012). To assess the level of inaccuracy in forecasting, the benchmarking instrument includes the MAPE one, three and six months ahead on product variant and product family levels, as shown in Table 1

\subsubsection{Vertical volatility}

Although long lead times have been identified as the most impactful source of vertical volatility, it was decided to incorporate the source of variable lead times into the benchmarking instrument since the length of lead time has to be assessed in combination with its variability in the context of SCV (Nitsche, 2018; Nitsche \& Durach, 2018).

To benchmark the SCV source of long lead times from a manufacturer's point of view, the user will be asked to state the supplier lead time (period of time between ordering a component at the supplier and the supplier having it ready for shipment) for suppliers of A-level components (based on a traditional $A B C$ analysis) belonging to the product as well as their transportation lead time (period of time between having the component picked at the supplier and having it transported to the designated production site). Additionally, the average production lead time of the final product as well as the delivery lead time (period of time between shipping a customer order and having it received by the customer) to the manufacturer's A-level customers has to be defined.

Although long lead times induce SCV, they could be manageable if lead times are always accurate and therefore plannable. In reality, real-world SC lead times vary, making the planning process inaccurate, which consequently causes SCV. To include this aspect in the SCV benchmarking instrument, the source of variable lead times will also be assessed. Therefore, the on-time delivery rate (OTDR, percentage of goods delivered on time (Chan, 2003)) of suppliers of A-level components of the product as well as the OTDR to the A-level customers has to be stated as an indicator of variable lead times. Additionally, the spread of lead times at the supply side is benchmarked by asking the user to indicate, for the majority of deliveries (set at 95\%), the minimum and maximum times required to order them from the supplier and have them shipped to and received at the production site. The necessary variables to assess the level of vertical volatility are outlined in Table 2.

Table 2. Variables to assess vertical volatility.

\begin{tabular}{|c|c|c|c|}
\hline & $\begin{array}{l}\text { Variable } \\
\text { name }\end{array}$ & $\begin{array}{l}\text { Type of } \\
\text { variable }\end{array}$ & Description \\
\hline \multirow{4}{*}{ 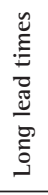 } & $\mathrm{LTS}_{\mathrm{i}}$ & $\mathrm{R}[0 ; \infty[$ & supplier lead time of supplier $i$ in days \\
\hline & $\mathrm{LTT}_{\mathrm{i}}$ & $\mathrm{R}[0 ; \infty[$ & transportation lead time from supplier $i$ in days \\
\hline & LTP & $\mathrm{R}[0 ; \infty[$ & production lead time in days \\
\hline & $\mathrm{LTC}_{\mathrm{j}}$ & $\mathrm{R}[0 ; \infty[$ & delivery lead time to customer $j$ in days \\
\hline \multirow{3}{*}{ 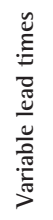 } & OTDS $_{i}$ & $\mathrm{R}[0 ; 1]$ & on-time delivery rare of supplier $i$ \\
\hline & $\mathrm{OTDC}_{\mathrm{j}}$ & $\mathrm{R}[0 ; 1]$ & on-time delivery rate to customer $j$ \\
\hline & $\mathrm{SP}_{\mathrm{i}}$ & $\mathrm{R}[0 ; \infty[$ & $\begin{array}{l}\text { time window of arrival of majority of goods (95\%) of supplier } i \text { (longest time span - shortest time span between } \\
\text { ordering and receiving a good) }\end{array}$ \\
\hline
\end{tabular}

\subsubsection{Behavioral volatility}

Behavioral volatility is induced by erratic behavior of customers as well as erratic behavior of decision makers in the SC (Nitsche \& Durach, 2018). Both sources have been ranked among the most pressing sources of SCV by SC managers (Nitsche, 2018). To assess both sources, qualitative measures have been defined for the user of the benchmarking instrument to rate via a self-assessment exercise. 
Erratic behavior of customers is characterized by unpredictable customer demand that causes a supply and demand mismatch at the focal firm (Childerhouse et al., 2008; Germain et al., 2008). This can be caused by changing customer preferences, fads, short-term order changes or cancellations, and others (Childerhouse et al., 2008; Germain et al., 2008; Johnson, 2001; So \& Zheng, 2003; Van der Vorst et al., 1998). Erratic behavior of decision makers in the supply chain involves decisions that are perceived as irrational from the recipient's point of view (Nitsche, 2018) because they induce volatility along the supply chain. This can be caused by overreactions to certain demand signals (e.g., higher orders than usual, expected shortages), forward buying, ordering more than needed, drastically reducing safety stocks, and others (Lee et al., 1997; Lee, 2002; Nienhaus et al., 2006; Nyoman Pujawan, 2004; Wong \& Hvolby, 2007). The variables chosen to measure SCV caused by both sources are depicted in Table 3.

Table 3. Variables to assess behavioral volatility.

\begin{tabular}{|c|c|c|c|}
\hline & $\begin{array}{l}\text { Variable } \\
\text { name }\end{array}$ & $\begin{array}{l}\text { Type of } \\
\text { variable }\end{array}$ & $\begin{array}{c}\text { Description } \\
\text { (self-assessment, indicate to what extend you agree to the following statement, } 1 \text { (totally disagree) to } \\
7 \text { (totally agree) }\end{array}$ \\
\hline \multirow{5}{*}{ 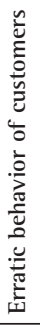 } & $\mathrm{EBC}_{1}$ & $\mathrm{Z}[1 ; 7]$ & In general, our customer demand is very hard to predict. \\
\hline & $\mathrm{EBC}_{2}$ & $\mathrm{Z}[1 ; 7]$ & Market trends are difficult to monitor because customer preferences change constantly. \\
\hline & $\mathrm{EBC}_{3}$ & $\mathrm{Z}[1 ; 7]$ & Our customers often adjust already placed orders. \\
\hline & $\mathrm{EBC}_{4}$ & $\mathrm{Z}[1 ; 7]$ & Customer loyalty to our brand is relatively low and the customer changes its preferences constantly. \\
\hline & $\mathrm{EBC}_{5}$ & $\mathrm{Z}[1 ; 7]$ & $\begin{array}{l}\text { Our customers often adjust orders (quantities or other specifications) in a short time window before planned } \\
\text { delivery. }\end{array}$ \\
\hline \multirow{2}{*}{ 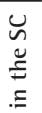 } & $\mathrm{EBD}_{1}$ & $\mathrm{Z}[1 ; 7]$ & At the end of the year we order more than we actually need to get a cash-back from our supplier. \\
\hline & $\mathrm{EBD}_{2}$ & $\mathrm{Z}[1 ; 7]$ & Sometimes we order more than actually needed in order "to be safe". \\
\hline \multirow{3}{*}{ 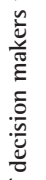 } & $\mathrm{EBD}_{3}$ & $\mathrm{Z}[1 ; 7]$ & Sometimes we order less than actually needed in order to reduce our safety stock level. \\
\hline & $\mathrm{EBD}_{4}$ & $\mathrm{Z}[1 ; 7]$ & $\begin{array}{l}\text { Due to lack of confidence in our IT system we adjust order quantities that are generated by the system based on } \\
\text { personal experience. }\end{array}$ \\
\hline & $\mathrm{EBD}_{5}$ & $\mathrm{Z}[1 ; 7]$ & $\begin{array}{l}\text { Due to lack of confidence in our IT system we adjust forecasts that are generated by the system based on personal } \\
\text { feelings. }\end{array}$ \\
\hline \multirow{4}{*}{ 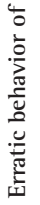 } & $\mathrm{EBD}_{6}$ & $\mathrm{Z}[1 ; 7]$ & When we expect a shortage of a component (not clear yet), we order more than actually needed. \\
\hline & $\mathrm{EBD}_{7}$ & $\mathrm{Z}[1 ; 7]$ & Sales people place customer orders early in advance before an actual customer order exists. \\
\hline & $\mathrm{EBD}_{8}$ & $\mathrm{Z}[1 ; 7]$ & If the actual demand in one month is higher or lower than planned demand, we immediately adjust our future plans. \\
\hline & $\mathrm{EBD}_{9}$ & $\mathrm{Z}[1 ; 7]$ & If we expect a price increase in the near future, we order more than we actually need to benefit from the current price. \\
\hline
\end{tabular}

\subsubsection{Market-related volatility}

Prior research evaluated high level of competition as the most important source of market-related volatility (Nitsche, 2018). Fierce competition is, inter alia, characterized by a high number of product variants offered by the focal firm itself and/or a high number of substitutes offered at the market (Randall \& Ulrich, 2001; Taylor \& Fearne, 2009), leading to greater demand volatility at the single part level. Additionally, if competitors are fighting for the same source of supply, a consequence can be volatile material flows originating on the supply side (Nitsche, 2018). Table 4 outlines the qualitative variables chose for assessing the dimension of market-related volatility.

Table 4. Variables to assess market-related volatility.

\begin{tabular}{|c|c|c|c|}
\hline & $\begin{array}{c}\text { Variable } \\
\text { name }\end{array}$ & $\begin{array}{l}\text { Type of } \\
\text { variable }\end{array}$ & $\begin{array}{c}\text { Description } \\
\text { (self-assessment, indicate to what extend you agree to the following statement, } 1 \text { (totally disagree) to } \\
7 \text { (totally agree) }\end{array}$ \\
\hline \multirow{6}{*}{ 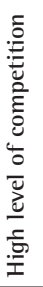 } & $\mathrm{HC}_{1}$ & $\mathrm{Z}[1 ; 7]$ & We often lose customers to our direct competitors. \\
\hline & $\mathrm{HC}_{2}$ & $\mathrm{Z}[1 ; 7]$ & We are forced to an intense price competition with our competitors. \\
\hline & $\mathrm{HC}_{3}$ & $\mathrm{Z}[1 ; 7]$ & We often have to rely on the same suppliers as our direct competitors. \\
\hline & $\mathrm{HC}_{4}$ & $\mathrm{Z}[1 ; 7]$ & In our market, it is difficult for us to differentiate ourselves from our competitors. \\
\hline & $\mathrm{HC}_{5}$ & $\mathrm{Z}[1 ; 7]$ & We offer a high number of product variants of our representative product. \\
\hline & $\mathrm{HC}_{6}$ & $\mathrm{Z}[1 ; 7]$ & There is a high number of substitutes for our representative product at the market. \\
\hline
\end{tabular}




\subsection{Benchmarking instrument}

The basic idea of the benchmarking instrument is that a user who would like to assess SCV affecting a product's SC will benchmark his volatility management performance against others. Therefore, he inserts data that have previously been collected and this is subsequently benchmarked against data from other manufacturers with the objective of identifying areas on which to focus when trying to manage volatility. SCV is a reality in all supply chains and cannot be completely eradicated. However, in order to stay competitive, managers need to know in what areas their volatility management performance is worse than the performance of others in order to initiate purposeful management measures. The benchmark that builds the basis for this instrument was developed through an online survey with 87 participating manufacturing firms from different industries. Based on their feedback, a user of the benchmarking instrument can assess the SCV of their product's SC.

The assessment itself is done through a weighted scoring model that calculates volatility scores from 1 (low volatility) to 10 (high volatility) for four dimensions of SCV as well as an overall SCV score for the product's $\mathrm{SC}$. In this way, the user will be enabled to dig deeper into the assessment, seeking to identify certain areas on which to focus when managing SCV. Figure 1 provides a schematic representation of the general structure of the benchmarking instrument. Every input variable has to be benchmarked using the benchmarking tables. Therefore, the user has to check which group the input variable has to be assigned to and choose the corresponding score. The calculation of the output scores of the volatility dimensions as well as the overall SCV score will be further described in the following sub-sections.

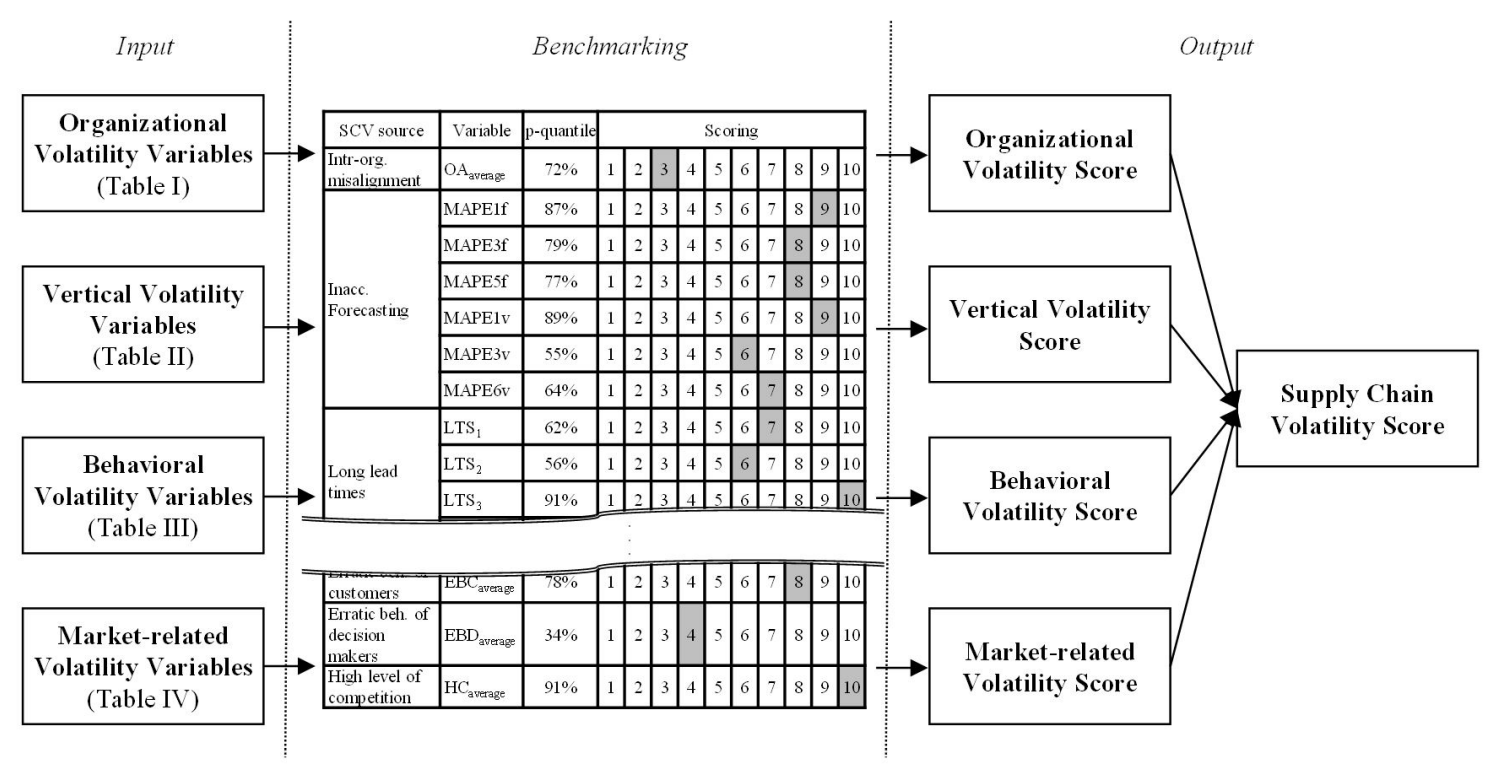

Figure 1. Exemplary schematic representation of the structure of the benchmarking instrument.

\subsubsection{Organizational volatility score}

The Organizational Volatility Score $\left(\mathrm{SC}_{\mathrm{ov}}\right)$ is calculated as the mean of the sub-scores for intra-organizational misalignment $\left(\mathrm{SC}_{\mathrm{OA}}\right)$ and inaccurate forecasting $\left(\mathrm{SC}_{\mathrm{MAPE}}\right)$ :

$$
S C_{O V}=0.5 \cdot S C_{O A}+0.5 \cdot S C_{M A P E}
$$

The $\mathrm{SC}_{\mathrm{OA}}$ is derived from the benchmarking of the mean of the input variables $\mathrm{OA}_{1}$ to $\mathrm{OA}_{6}$. The $\mathrm{SC}_{\mathrm{MAPE}}$ results from the benchmarking of MAPE variables described in Table 1. In general, a lower MAPE one month ahead is of higher importance in the context of SCV than a low six month ahead MAPE, since more expensive measures have to be undertaken to match supply and demand in the short term (e.g., short-term air freight instead of sea freight, higher stock expenses). Hence, to calculate the $\mathrm{SC}_{\text {MAPE }}$ a weighting is applied to incorporate the higher importance of a short-term MAPE over a mid-term and long-term MAPE into the $\mathrm{SC}_{\text {MAPE }}$ calculation: 


$$
S C_{M A P E}=0.3 \cdot S C_{M A P E 1 f}+0.3 \cdot S C_{M A P E I v}+0.15 \cdot S C_{M A P E 3 f}+0.15 \cdot S C_{M A P E 3 v}+0.05 \cdot S C_{M A P E 6 f}+0.05 \cdot S C_{M A P E 6 v}
$$

Without a doubt, the weighting itself can be questioned, since it is not based on prior research, but the higher impact of a poor short-term MAPE over a poor mid-term and long-term MAPE has been stated by multiple practitioners who were involved throughout the process. Nevertheless, in certain circumstances where a six month ahead MAPE is of high importance (e.g. if necessary components for production have very long supplier lead times of more than six months), this weighting can be adjusted by the user of the benchmarking instrument.

\subsubsection{Vertical volatility score}

Not only will the user of the benchmarking instrument be enabled to assess the level of volatility that is induced by the company itself, as in the case of the $\mathrm{SC}_{\mathrm{ov}}$, but the instrument will also enable the assessment of the effect of certain members in the supply chain (e.g., suppliers, customers) on SCV. The Vertical Volatility Score $\left(\mathrm{SC}_{\mathrm{W}}\right)$ is calculated as the mean of the two sub-scores of the assessment of long lead times $\left(\mathrm{SC}_{\mathrm{LLT}}\right)$ and variable lead times $\left(\mathrm{SC}_{\mathrm{VLT}}\right)$ :

$$
S C_{V V}=0.5 \cdot S C_{L L T}+0.5 \cdot S C_{V L T}
$$

To assess SCV induced by long lead times ( $\mathrm{SC}_{\mathrm{LTT}}$ ), different input variables have been defined, as shown in Table 2. $\mathrm{SC}_{\mathrm{LLT}}$ itself incorporates four sub-scores for the impact of supplier lead time $\left(\mathrm{SC}_{\mathrm{LTS}}\right)$, transportation lead time $\left(\mathrm{SC}_{\mathrm{LTT}}\right)$, production lead time ( $\left.\mathrm{SC}_{\mathrm{LTP}}\right)$, and delivery lead time $\left(\mathrm{SC}_{\mathrm{LTC}}\right)$.

In general, those four lead times sum up to the supply chain lead time $\left(\mathrm{t}_{\text {total }}\right)$, the time span between ordering components at a supplier and having the final product shipped to the customer. The longer the lead time gets, the more devastating the effects on SCV become. This being said, it is proposed to weight the sub-scores by the share of their respective lead time on the total supply chain lead time. It is therefore proposed to use the median values of all supplier lead times $\left(\mathrm{t}_{\mathrm{LTS}}\right)$, transportation lead times $\left(\mathrm{t}_{\mathrm{LTT}}\right)$, production lead times $\left(\mathrm{t}_{\mathrm{LTP}}\right)$, and delivery lead times $\left(\mathrm{t}_{\mathrm{LTC}}\right)$ and relate them to the median total supply chain lead time of the products SC $\left(\mathrm{t}_{\text {total }}\right)$ :

$$
S C_{L L T}=\frac{t_{L T S}}{t_{\text {total }}} \cdot S C_{L T S}+\frac{t_{L T T}}{t_{\text {total }}} \cdot S C_{L T T}+\frac{t_{L T P}}{t_{\text {total }}} \cdot S C_{L T P}+\frac{t_{L T C}}{t_{\text {total }}} \cdot S C_{L T C}
$$

To calculate the sub-scores $\mathrm{SC}_{\mathrm{LTS}}$ and $\mathrm{SC}_{\mathrm{LTT}}$ it is proposed to weight the scores for each supplier by the share of purchasing volume of supplier $i\left(\mathrm{ps}_{\mathrm{i}}\right)$ in the total purchasing volume for the assessed product ( $\left.\mathrm{ps}_{\text {total }}\right)$. The same will be applied for $\mathrm{SC}_{\text {LTC }}$, where the score of each customer will be weighted by the share of the sales volume of the customer $\left(\mathrm{pc}_{\mathrm{f}}\right)$ in the total sales volume of the investigated product $\left(\mathrm{pc}_{\text {total }}\right)$. The sub-score for the production lead time $\left(\mathrm{SC}_{\mathrm{LTP}}\right)$ results from the benchmarking of the product's production lead time (LTP) using the benchmarking tables independently from suppliers or customers.

$$
\begin{aligned}
S C_{L T S} & =\sum_{i}\left(\frac{p s_{i}}{p s_{\text {total }}} \cdot S C_{L_{\text {TSS }}}\right) \\
S C_{\text {LTT }} & =\sum_{i}\left(\frac{p s_{i}}{p s_{\text {total }}} \cdot S C_{L T T_{i}}\right) \\
S C_{L T C} & =\sum_{j}\left(\frac{p c_{j}}{p c_{\text {total }}} \cdot S C_{\text {LTC }_{j}}\right)
\end{aligned}
$$

The assessment of volatility induced by variable lead times $\left(\mathrm{SC}_{\mathrm{VLT}}\right)$ includes three sub-scores, in particular for the on-time delivery rate of suppliers $\left(\mathrm{SC}_{\text {отDS }}\right)$, the on-time delivery rate to customers $\left(\mathrm{SC}_{\mathrm{OTDC}}\right)$, and for time window of incoming deliveries $\left(\mathrm{SC}_{\mathrm{SP}}\right) . \mathrm{SC}_{\mathrm{VLT}}$ will be calculated as the mean of those three sub-scores.

$$
S C_{V L T}=\frac{1}{3} \cdot S C_{O T D S}+\frac{1}{3} \cdot S C_{O T D C}+\frac{1}{3} \cdot S C_{S P}
$$

As previously explained, the scores of each supplier for $\mathrm{SC}_{\text {ОTDS }}$ and $\mathrm{SC}_{\mathrm{SP}}$ will be weighted by the share of the purchasing volume of the supplier in the total purchasing volume. Consequently, the $\mathrm{SC}_{\text {отрс }}$ for each customer will be weighted by the share of sales volume of the customer in the total sales volume of the investigated product: 


$$
\begin{aligned}
S C_{\text {OTDS }} & =\sum_{i}\left(\frac{p s_{i}}{p s_{\text {total }}} \cdot S C_{\text {OTDS }}\right) \\
S C_{\text {OTDC }} & =\sum_{j}\left(\frac{p c_{j}}{p c_{\text {total }}} \cdot S C_{O T D C_{j}}\right) \\
S C_{S P} & =\sum_{i}\left(\frac{p s_{i}}{p s_{\text {total }}} \cdot S C_{S P_{i}}\right)
\end{aligned}
$$

In providing all the inputs described, the user of the tool will be enabled not only to assess vertical volatility in their product's SC, but also to assess which supplier or customer contributes most to the volatility that affects their product's SC.

\subsubsection{Behavioral volatility score}

The Behavioral Volatility Score $\left(\mathrm{SC}_{\mathrm{Bv}}\right)$ is calculated as the mean of the two sub-scores for erratic behavior of customers $\left(\mathrm{SC}_{\mathrm{EBC}}\right)$ and erratic behavior of decision makers $\left(\mathrm{SC}_{\mathrm{EBD}}\right)$. Those sub-scores themselves result from the benchmarking of the mean of the input variables EBC and EBD, as described in Table 3.

$$
S C_{B V}=0.5 \cdot S C_{E B C}+0.5 \cdot S C_{E B D}
$$

\subsubsection{Market-related volatility score}

To assess market-related volatility, the source of high level of competition is measured via a qualitative self-assessment of six variables as described in Table 4. Thus, the Market-related Volatility Score $\left(\mathrm{SC}_{\mathrm{MV}}\right)$ results from the benchmarking of the mean of those input variables.

\subsubsection{Supply chain volatility score}

To calculate the total $\mathrm{SCV}$ score $\left(\mathrm{SC}_{\mathrm{SCV}}\right.$ ) of a product, $\mathrm{SC}, \mathrm{SC}_{\mathrm{OV}}, \mathrm{SC}_{\mathrm{W}}, \mathrm{SC}_{\mathrm{BV}}$ and $\mathrm{SC}_{\mathrm{MV}}$ are necessary. As proposed by Nitsche (2018), the corresponding four volatility dimensions do not impact SCV equally. Based on an AHP among SC practitioners, Nitsche (2018) assessed the impact of those four dimensions on SCV. In addition, he contextualized this impact by the production strategy of the manufacturing firm and proposed that the impacts of those four dimensions differ significantly between make to order and make to stock supply chains. Building on these findings, it is prosed to apply Nitsche (2018) proposed weightings to calculate $\mathrm{SC}_{\mathrm{sc}}$, and the weighing factor $\alpha$ is therefore introduced. The user of the benchmarking instrument has to decide whether he wants to apply the overall weighting factors including all production strategies (including engineer to order), or the weighting factors for either make to order or make to stock production strategies, as proposed by Nitsche (2018). The corresponding weightings are outlined in Table 5.

Table 5. Weighting factors for the calculation of the overall supply chain volatility score.

\begin{tabular}{cccc}
\hline Weighting factor & $\begin{array}{c}\text { Independent from production } \\
\text { strategy }\end{array}$ & $\begin{array}{c}\text { Make to order production } \\
\text { strategy }\end{array}$ & $\begin{array}{c}\text { Make to stock production } \\
\text { strategy }\end{array}$ \\
\hline$\alpha_{\mathrm{OV}}$ & 0.341 & 0.451 & 0.277 \\
$\alpha_{\mathrm{VV}}$ & 0.276 & 0.296 & 0.234 \\
$\alpha_{\mathrm{BV}}$ & 0.203 & 0.168 & 0.187 \\
$\alpha_{\mathrm{MV}}$ & 0.179 & 0.085 & 0.301 \\
\hline
\end{tabular}

Consequently, $\mathrm{SC}_{\mathrm{SCv}}$ is calculated as the sum of dimensional volatility scores multiplied by their corresponding weighting factor:

$$
S C_{S C V}=\alpha_{O V} \cdot S C_{O V}+\alpha_{V V} \cdot S C_{V V}+\alpha_{B V} \cdot S C_{B V}+\alpha_{M V} \cdot S C_{M V}
$$




\section{Current state of supply chain volatility management performance}

\subsection{Sample description}

To gather required benchmarking data, a survey among manufacturing firms operating in different industries was conducted from June to July 2018. This was intended to cover a heterogeneous group drawn from different types of manufacturing firms. To complete the survey, participants first had to fill in general company-related data and afterwards had to think of a representative product that is manufactured by their company and that they know very well. Subsequently, all questions were asked with reference to the representative product. In total, 87 responses were collected from different manufacturing industries, mainly from the machinery/equipment, automotive, consumer goods, and chemicals/pharmaceuticals sectors. The surveyed products mostly had make to order/assemble to order and make to stock production strategies, and their production sites were mostly located in western Europe. The sample demographics are outlined in Table 6.

Table 6. Sample demographics of SCV benchmarking.

\begin{tabular}{|c|c|c|c|c|c|c|c|c|c|c|c|c|c|}
\hline \multicolumn{8}{|c|}{ Company-related } & \multicolumn{6}{|c|}{ Product-related } \\
\hline \multicolumn{2}{|l|}{$\begin{array}{l}\text { Manufacturing } \\
\text { industry }\end{array}$} & \multicolumn{2}{|c|}{ SC position * } & \multicolumn{2}{|c|}{ Total annual turnover } & \multicolumn{2}{|c|}{$\begin{array}{l}\text { number of } \\
\text { employees }\end{array}$} & \multicolumn{2}{|l|}{$\begin{array}{l}\text { Production } \\
\text { strategy ** }\end{array}$} & \multicolumn{2}{|c|}{$\begin{array}{l}\text { Turnover with } \\
\text { the product }\end{array}$} & \multicolumn{2}{|c|}{$\begin{array}{l}\text { Location of main } \\
\text { production site }\end{array}$} \\
\hline $\begin{array}{l}\text { Consumer } \\
\text { goods }\end{array}$ & 15 & OEM & 54 & $\begin{array}{l}\text { up to } \\
50 m €\end{array}$ & 6 & up to 50 & 0 & $\begin{array}{c}\text { Make to } \\
\text { order/ } \\
\text { assemble to } \\
\text { order }\end{array}$ & 44 & $1-10 m €$ & 9 & $\begin{array}{l}\text { Western } \\
\text { Europe }\end{array}$ & 65 \\
\hline $\begin{array}{c}\text { Chemicals/ } \\
\text { pharmaceuticals }\end{array}$ & 13 & $\begin{array}{l}\text { Module/ } \\
\text { system } \\
\text { supplier } \\
\text { (1st tier) }\end{array}$ & 29 & $51-250 m €$ & 11 & $51-250$ & 6 & $\begin{array}{l}\text { Make to } \\
\text { stock }\end{array}$ & 33 & $11-100 m €$ & 24 & $\begin{array}{l}\text { Eastern } \\
\text { Europe }\end{array}$ & 4 \\
\hline Automotive & 20 & $\begin{array}{l}\text { Component } \\
\text { supplier } \\
\text { (2nd tier) }\end{array}$ & 12 & $\begin{array}{c}251- \\
500 m €\end{array}$ & 11 & $251-500$ & 7 & $\begin{array}{l}\text { Engineer to } \\
\text { order }\end{array}$ & 9 & $\begin{array}{c}101-250 \mathrm{~m} \\
€\end{array}$ & 14 & China & 10 \\
\hline Electronics & 8 & $\begin{array}{c}\text { Standardized } \\
\text { parts supplier } \\
\text { (3rd tier) }\end{array}$ & 2 & $\begin{array}{c}501- \\
1000 m €\end{array}$ & 12 & $\begin{array}{l}501- \\
1000\end{array}$ & 7 & & & $\begin{array}{c}251-500 \mathrm{~m} \\
€\end{array}$ & 10 & $\begin{array}{l}\text { South East } \\
\text { Asia }\end{array}$ & 3 \\
\hline $\begin{array}{l}\text { Machinery/ } \\
\text { equipment }\end{array}$ & 23 & $\begin{array}{c}\text { Raw material } \\
\text { supplier } \\
\text { (n-th tier) }\end{array}$ & 6 & $1-2.5 b n €$ & 11 & $\begin{array}{l}1001- \\
2500\end{array}$ & 10 & & & $\begin{array}{c}501-1000 \mathrm{~m} \\
€\end{array}$ & 7 & USA/Canada & 1 \\
\hline \multirow{3}{*}{ Others } & \multirow{3}{*}{8} & & \multirow{3}{*}{$\begin{array}{c}\text { more } \\
\text { than } \\
\text { 10bn } €\end{array}$} & $2.5-5 b n €$ & 6 & $\begin{array}{c}2501- \\
5000 \\
\end{array}$ & 11 & & & $>1$ bn $€$ & 20 & Others & 4 \\
\hline & & & & 5-10bn $€$ & 10 & $\begin{array}{l}5001- \\
10000 \\
\end{array}$ & 10 & & & & & & \\
\hline & & & & 20 & $\begin{array}{c}\text { more than } \\
10000\end{array}$ & 36 & & & & & & & \\
\hline
\end{tabular}

*multiple answers possible; **one participant refused to answer; ${ }^{* * *}$ three participants refused to answer.

\subsection{Benchmarking results}

Table 7 outlines the benchmarking results of all questionnaire participants. The average, median, and distribution of variables are detailed. The categories for the corresponding volatility scores are ranked in ten quantiles (deciles), meaning that the best values are assigned to the best decile and given the lowest volatility score of 1 , going up to a volatility score of 10 for the worst values assigned to the worst decile. Values that are very frequently represented sometimes form two or even three deciles. This means that the user must use the average of the respective scores for benchmarking.

It can be observed that best-in-class companies in the area of organizational alignment assess themselves with average scores of above 5.5 (on a 7-point likert scale), while the worst companies scored mean values below 3.27 for the six categories of organizational alignment.

For the SCV source of long lead times, the biggest share in the total lead time is associated with the supplier lead time (LTS), meaning that this area should be prioritized when trying to mitigate SCV originating from long lead times in the SC. Companies with an average of above 110 days of LTS for their main components form the worst decile of the companies investigated. Best-in-class companies achieve very low LTS for their main components of below five days. Although the median of on time delivery rates on the supply and demand 
Table 7. Benchmarking table including all production strategies.

\begin{tabular}{|c|c|c|c|c|c|c|c|c|c|c|c|c|c|c|}
\hline \multirow{3}{*}{ SCV dimension } & \multirow{3}{*}{ SCV source } & \multirow{3}{*}{$\begin{array}{c}\text { Input } \\
\text { Variable }\end{array}$} & \multirow{3}{*}{ Average } & \multirow{3}{*}{ Median } & \multicolumn{10}{|c|}{ Volatility Score } \\
\hline & & & & & \multicolumn{2}{|c|}{ Best in class } & \multicolumn{2}{|c|}{ Advanced } & \multicolumn{2}{|c|}{ Typical } & \multicolumn{2}{|c|}{ Catch up } & \multicolumn{2}{|c|}{ Latecomer } \\
\hline & & & & & 1 & 2 & 3 & 4 & 5 & 6 & 7 & 8 & 9 & 10 \\
\hline \multirow{7}{*}{$\begin{array}{c}\text { Organizational } \\
\text { Volatility }\end{array}$} & $\begin{array}{l}\text { Intra-org. } \\
\text { misalignment }\end{array}$ & OAavrg & 4.64 & 4.67 & $>=6.17$ & $>5.5$ & $>5.2$ & $>5$ & $>4.67$ & $>4.5$ & $>4$ & $>3.83$ & $>3.27$ & $<=3.27$ \\
\hline & \multirow{6}{*}{$\begin{array}{l}\text { Inaccurate } \\
\text { forecasting }\end{array}$} & MAPE1f & 9.27 & 6.00 & $<=2$ & $<4.8$ & \multicolumn{2}{|c|}{$<5$} & $<6$ & \multicolumn{2}{|c|}{$<10$} & $<11.8$ & $<20$ & $>=20$ \\
\hline & & MAPE3f & 15.67 & 15.00 & $<=5$ & $<6.6$ & \multicolumn{2}{|c|}{$<10$} & $<15$ & $<18$ & $<20$ & $<22$ & $<30$ & $>=30$ \\
\hline & & MAPE6f & 22.58 & 20.00 & $<=5$ & $<10$ & $<11.2$ & $<15$ & $<20$ & $<25$ & $<30$ & $<33$ & $<40$ & $>=40$ \\
\hline & & MAPE1v & 10.86 & 10.00 & $<=2.3$ & $<3.6$ & $<5$ & $<6.4$ & \multicolumn{2}{|c|}{$<10$} & $<10.1$ & $<15$ & $<20$ & $>=20$ \\
\hline & & MAPE3v & 17.98 & 15.00 & $<=5$ & $<8$ & \multicolumn{2}{|c|}{$<10$} & $<15$ & $<20$ & $<21.2$ & $<30$ & $<34.2$ & $>=34.2$ \\
\hline & & MAPE6V & 24.92 & 23.00 & $<=8$ & $<10$ & $<12.9$ & $<15.4$ & $<23$ & $<28$ & $<34.1$ & $<40$ & $<50$ & $>=50$ \\
\hline \multirow{7}{*}{$\begin{array}{l}\text { Vertical } \\
\text { Volatility }\end{array}$} & \multirow{4}{*}{ Long lead times } & LTS & 50.48 & 30.00 & $<=5$ & $<12.8$ & $<20$ & $<28.8$ & $<30$ & $<46.8$ & $<60$ & $<78.4$ & $<110.8$ & $>=110.8$ \\
\hline & & LTT & 11.04 & 5.00 & $<=1$ & $<2$ & $<3$ & $<4$ & \multicolumn{2}{|c|}{$<5$} & $<7.2$ & $<13.4$ & $<32.4$ & $>=32.4$ \\
\hline & & LTP & 25.06 & 7.00 & $<=0.6$ & $<1$ & $<3$ & $<5$ & $<7$ & $<10$ & $<17$ & $<30$ & $<73.6$ & $>=73.6$ \\
\hline & & LTC & 8.72 & 4.00 & $<=1$ & \multicolumn{2}{|c|}{$<2$} & $<3$ & $<4$ & $<5$ & $<7.3$ & $<10$ & $<20.7$ & $>=20.7$ \\
\hline & \multirow{3}{*}{$\begin{array}{l}\text { Variable lead } \\
\text { times }\end{array}$} & OTDS & 81.18 & 90.00 & $>=97$ & $>95$ & $>90.8$ & \multicolumn{2}{|c|}{$>90$} & $>84.86$ & $>80$ & $>75$ & $>52$ & $<=52$ \\
\hline & & OTDC & 87.28 & 92.00 & $>98.9$ & $>98$ & $>95$ & $>94.6$ & $>92$ & \multicolumn{2}{|c|}{$>90$} & $>81$ & $>70.5$ & $<=70.5$ \\
\hline & & SP & 39.04 & 25.00 & $<=4$ & $<6.8$ & $<11$ & $<16.2$ & $<25$ & $<30$ & $<40$ & $<48.4$ & $<94$ & $<=94$ \\
\hline \multirow{2}{*}{$\begin{array}{l}\text { Behavioral } \\
\text { Volatility }\end{array}$} & $\begin{array}{c}\text { Erratic behavior } \\
\text { of customers }\end{array}$ & EBCavrg & 3.62 & 3.60 & $<=2$ & $<2.6$ & $<3$ & $<3.28$ & $<3.6$ & $<3.8$ & $<4.2$ & $<4.6$ & $<5.2$ & $>=5.2$ \\
\hline & $\begin{array}{c}\text { Erratic behavior } \\
\text { of DM }\end{array}$ & EBDavrg & 3.73 & 3.89 & $<=2.44$ & $<2.78$ & $<3.31$ & $<3.6$ & $<3.89$ & $<4.07$ & $<4.33$ & $<4.44$ & $<4.93$ & $>=4.93$ \\
\hline $\begin{array}{l}\text { Market-related } \\
\text { Volatility }\end{array}$ & $\begin{array}{l}\text { High level of } \\
\text { competition }\end{array}$ & HCavrg & 4.22 & 4.17 & $<=2.87$ & $<3.33$ & $<3.83$ & $<4$ & $<4.17$ & $<4.5$ & $<4.67$ & $<5$ & $<5.5$ & $>=5.5$ \\
\hline
\end{tabular}

sides (OTDS and OTDC) are 90 percent and 92 percent, respectively, the best companies demonstrate delivery reliabilities above 99 percent.

For sources of behavioral volatility, the majority of participants rank themselves with scores below 4 (7-point Likert scale), meaning that a high level of erratic behavior of decision makers as well as erratic behavior of customers is not a given in all supply chains. However, companies with erratic behavior scores of above 5 rank among the worst in class, resulting in a high level of SCV originating from the behavioral dimension.

A more detailed assessment of the benchmarking values, analyzed according to the production strategies for the products of the participating manufacturing firms, is outlined in Table 8. Although values do not differ immensely, it can be observed that MTO companies seem to have better intra-organizational alignment that MTS companies. This result stands in contrast to previous findings of Nitsche (2018), who proposed that companies with make to order production strategies are exposed to a high degree of intra-organizational misalignment since intra-organizational processes for MTO products are not as well defined as for MTS products. With regard to forecasting, it is interesting to see that, based on the median values, MTS companies seem to perform better than or as well as MTO companies one month in advance on a product family and variant level. However, three and six months in advance, MTO companies achieve better MAPE values, in some cases significantly so, than MTS companies.

According to the length of SC lead times, the best 10 percent of MTO companies achieve shorter lead times for all four lead time categories than MTS companies. However, comparing the median values of both groups, MTS companies manage to achieve shorter lead times on the supply side. For transportation lead times, although median values are the same, it can be observed that MTS companies in the catch up and latecomers groups score significantly higher lead times than MTO companies. The worst 10 percent of MTS companies score above 44 days of transportation lead time for their A-level components, while the worst MT0 companies manage to achieve at least 13.1 days of transportation lead time. Based on this result, it seems that MTS companies rely more on global sourcing than MTO companies. This could indicate that MTO companies, in order to reduce waiting times for their customers, rely more on suppliers from their region. Also, for the variability of lead times, differences between MTO and MTS companies can be observed. Both on the supply side as well as on the customer side, MTS companies manage to achieve significantly better on-time delivery rates than MTO companies.

According to the dimension of behavioral volatility as well as for the dimension of market-related volatility, slight differences between both production strategies can be observed, but they are not significant. 


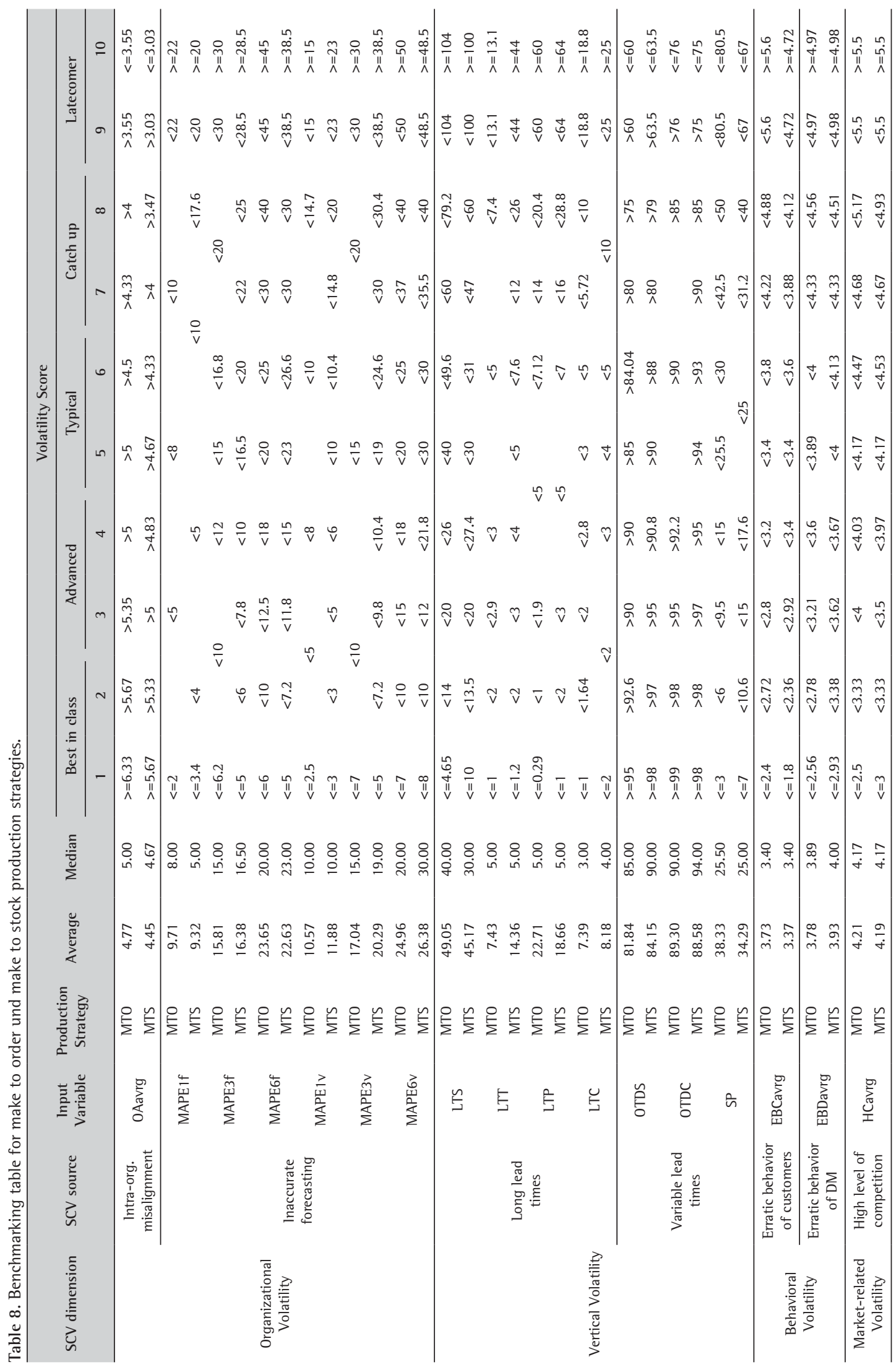




\section{Exemplary application in the automotive industry}

To demonstrate the applicability of the developed instrument, a confirmatory case study was performed. Therefore, the authors received necessary data from the case study company and assessed their state of SCV management based on the benchmarking instrument described above. Afterwards, the results were discussed with two representatives of the case study company to evaluate the applicability and whether the benchmarking results meets the perception of the case study company.

The case study company Motion Tech (the name of the company has been changed) is a globally operating supplier for bearings, clutches and different sorts of customized modules for the automotive industry. With more than 50,000 employees and an annual turnover of over 10 billion euros, Motion Tech is among the leading suppliers in the automotive industry. In the investigated case, Motion Tech serves as a first-tier supplier for clutches operating with a MTO production strategy. The corresponding manufacturing site is located in Germany. Following the computation of input data provided by Motion Tech, the benchmarking result was calculated (see Figure 2).

\begin{tabular}{|lr|}
\hline Results & Score \\
\hline & \\
\hline Organizational Volatility & 3.30 \\
\hline Intra-Organizational misaligment & 3.00 \\
Inaccurate forecasting & 3.60 \\
& \\
\hline Vertical Volatility & $\mathbf{7 . 1 5}$ \\
\hline Long lead times & 9.64 \\
Supplier lead time & 10.00 \\
Transportation lead time & 8.00 \\
Production lead time & 7.00 \\
Delivery lead time & 10.00 \\
Lead time variability & 4.67 \\
& \\
\hline Behavioral Volatility & 4.50 \\
\hline \hline erratic behavior of customers & 4.00 \\
Erratic behavior of decision makers in the SC & 5.00 \\
\hline Market-related Volatility & $\mathbf{2 . 0 0}$ \\
\hline \hline high level of competition & 2.00 \\
& \\
Ove rall Volatility Score & 4.24 \\
\hline
\end{tabular}

Figure 2. SCV assessment of case study company resulting from a benchmarking against manufacturers with MTO production strategy.

Looking into the results it can be observed that Motion Tech score an above average overall score of 4.24. To identify areas for improvement, the four dimensions have to be analyzed in detail. Motion Tech has an advanced score in intra-organization alignment and forecasting, leading to a score of 3.3 for organizational volatility. Especially for short-term forecasting one month in advance, Motion Tech's forecasting error (MAPE) of $2 \%$ is among the lowest of all benchmarking participants. SCV perceived at Motion Tech is - according to the benchmarking instrument - mainly caused by the dimension of vertical volatility, more specifically very long lead times. Their average supplier lead time ranks among the worst of all benchmarking participants. The same holds true for the delivery lead time of 20 days to their main customers, which also ranks among the worst $10 \%$ of all benchmarking participants. Consequently, Motion Tech should focus on reducing their lead times significantly in order to reduce volatility along their SC. This result was also supported by both employees of Motion Tech. They argued that their SC network is internationally dispersed and, especially on the supply side, a large share of suppliers for their plant in Germany originate from North America and China. They agreed with the recommendation that they should strongly focus on localizing their supply base in order to reduce volatility. The low level of market-related volatility that has been assessed, which is measured by the level of competition in the market, is confirmed by Motion Tech's employees. According to them, they have around three relevant competitors in their market, but the level of competition is relatively low. Since their products are mostly highly customized products, their customers are not able to replace them as their supplier at short notice. 
In general, it can be stated, that in this specific case the benchmarking instrument provided valuable insights for the case study and the results were consistent with the subjective perception of Motion Tech's employees about their current state of SCV management. However, during the discussion some limitations have been identified that will be discussed in the "Conclusion and Final Remarks" section.

\section{Implications}

The aim of this study has been to propose a benchmarking instrument that enables SC managers to critically assess the current state of SCV for their products' SCs. Building on prior research in the field of SCV management, the benchmarking instrument assesses SCV according to four distinct dimensions of SCV. The assessment was done via a benchmarking exercise conducted among 87 manufacturing firms that are ranked according to their SCV management performance within those four dimensions.

For managers, the benchmarking instrument enables them to investigate the volatility of a product's SC and monitor it in the long-run, seeking to identify areas on which to focus when trying to manage SCV efficiently. With the help of the instrument, they are able to assess whether the volatility of their product's SC is induced by themselves, by certain actors within their supply chain, by a high level of competition in the market, or by irrational behavioral patterns of customers or decision makers in the SC. Thus, the study is the first of its kind that facilitates a holistic assessment of SCV, one of the core phenomena in SCM. Consequently, the user of the tool will be able to track down the most pressing sources of SCV for their specific case.

In addition, this study provides valuable information for practitioners about the current state of volatility management performance in the manufacturing sector. Based on the feedback from 87 manufacturing firms, a benchmark has been condensed and incorporated into the SCV assessment tool that facilitates managers to compare their SCV management performance against others. This is of high importance since performance data generated by the focal firm itself are more valuable if they can be put into context with the performance data of competitors. To add more value to this, the benchmark has been further contextualized according to the production strategy of the participating manufacturing firm. It can be observed that for some variables there are essential differences between make to order and make to stock production strategies, which adds further depth to the analysis of SCV performance.

For researchers, the study provides a holistic approach to measure the volatility of a product's SC which can be the basis for further research. Prior research in the assessment of SCV evaluated volatility in SCs from a macroeconomic perspective via measuring the volatility of exchange rates, raw material prices, and other factors (Christopher \& Holweg, 2011, 2017). Although it is of importance to measure and monitor the volatility of SCM-related market prices, from a practitioner point of view, a case-based evaluation of their specific state of $\mathrm{SCV}$ is necessary to derive SC-specific information and initiate more purposeful actions from it.

\section{Conclusion and final remarks}

By incorporating volatility management performance data from 87 manufacturing firms, this paper proposes a benchmarking instrument that enables a case-based assessment of the SCV management performance of a manufacturer. For practitioners especially, it is important to identify areas on which to focus when seeking to manage SCV observed in their products' SCs. However, like every study, this one also has limitations that must be pointed out.

First, the benchmarking data gathered from 87 manufacturing firms provides a solid basis, but has to be extended to a larger scale in order to be more reliable. The current sample size is, on the one hand, large enough to enable the intended benchmarking, but, on the other, is too small to extract more fine-grained analyses.

Second, the contextualization of benchmarking data according to make to order and make to stock production strategies adds depth to the analysis of benchmarking but can only be understood as a starting point for further contextualization that is still necessary. Since it is the first study of its kind, it was intended to cover a heterogeneous group of manufacturing companies, but for future analyses the sample size needs to be increased and should be focused only on certain industries. In particular, a more in-depth analysis of benchmarking data according to different manufacturing industries (automotive, consumer goods, and others) would be necessary and of particular relevance for practitioners, since this would enable them to benchmark themselves against their competitors. Unfortunately, due to the sample demographics described in Table 6, such an analysis could not reliably be undertaken.

Third, the proposed benchmarking instrument assesses the impact of certain SCV sources on volatility of a product's SC via a benchmarking of volatility management performance data. It thereby assesses the performance 
of a product's SC in a certain category according to the benchmark, but it does not relate this to the impact on overall company performance. This being said, this study has to be understood as a call for further quantitative research on the impact of SCV sources on company performance.

Fourth, the measuring instrument assesses the volatility performance in certain areas of volatility management but does not relate this performance with the resulting costs of achieving a good performance score in a particular category. For example, if a company achieves very high on-time delivery rates on the supply and demand sides, the company gets a low volatility score for the source of variable lead times, which indicates to them good volatility management performance in that category. But the measuring instrument does not take into account at what cost this performance has been achieved. In the described case, the company argued that they invest a lot into special freight to maintain good on-time delivery rates. However, the relationship between cost and volatility management performance certainly is of importance but was beyond the scope of this research paper and still remains an area for future research.

Fifth, the benchmarking instrument is based on a weighted scoring model. Therefore, assumptions had to be made. Although the calculation of the overall Supply Chain Volatility Score $\left(\mathrm{SC}_{\mathrm{SCV}}\right)$ is based on weights proposed by Nitsche (2018), for the calculation of corresponding sub-scores assumptions were necessary. For example, to calculate $\mathrm{SC}_{0 \mathrm{~V}}$ the calculation of the sub-score $\mathrm{SC}_{\text {MAPE }}$ is necessary that expresses the impact of inaccurate forecasting on SCV. Therefore, we assumed that an inaccurate short-term MAPE (one month ahead) on product variant or family level has a bigger impact on a bad overall SCV score that an inaccurate medium and long-term MAPE (three or six months ahead) since more expensive countermeasures have to be initiated to avoid negative effects of inaccurate forecasting. Although this assumption seems intuitive and was based on practitioners' feedback that have been involved in the instrument building process, it was not based on quantitative research and situations might occur where this assumption does not hold true and the user of the instrument has to adjust the weights. This being said, the weights to calculate all sub-scores were based on assumptions and further quantitative testing would be necessary to come to more fine-grained weights.

Sixth, although we aimed at reducing bias in the procedure of variable definition for the benchmarking instrument by involving additional feedback from researchers and practitioners, the variables chosen were partially based assumptions and other variables could have been useful as well. Since previous research on managing SCV did not focus on measuring the performance of SCV management, this study has to be understood as a first step in this area and further research on how to measure SCV is still necessary.

Nevertheless, the study extends prior research on the assessment of SCV that has so far taken a macroeconomic perspective by adding a microeconomic view that is of particular importance for SC managers who are managing SCV on a daily basis. To the best of the authors' knowledge, the study is the first of its kind that seeks to assesses SCV management performance in a holistic way.

\section{Final note}

This article presents an extended version of a conference paper that has been presented at the 2018 POMS conference in Rio de Janeiro, Brazil. The conference paper has been published in the Springer proceedings of the conference (Leiras et al., 2019). The extended version of the article is also part of a cumulative thesis that has already been published (Nitsche, 2019).

\section{Acknowledgements}

The authors would like to thank the Kuehne Foundation for the financial support of this study.

\section{References}

Acquaye, A., Genovese, A., Barrett, J., \& Lenny Koh, S. C. (2014). Benchmarking carbon emissions performance in supply chains. Supply Chain Management, 19(3), 306-321. http://dx.doi.org/10.1108/SCM-11-2013-0419.

Aven, T. (2016). Risk assessment and risk management: review of recent advances on their foundation. European Journal of Operational Research, 253(1), 1-13. http://dx.doi.org/10.1016/j.ejor.2015.12.023.

Beamon, B. M. (1999). Measuring supply chain performance. International Journal of Operations \& Production Management, 19(3), 275-292. http://dx.doi.org/10.1108/01443579910249714.

Bowerman, B. L., O’Connell, R. T., Koehler, A. B., \& Bowerman, B. L. (2005). Forecasting, time series, and regression: an applied approach (4th ed.). Belmont: Thomson Brooks/Cole.

Camp, R. C. (1989). Benchmarking: the search for industry best practices that lead to superior performance. Milwaukee: Quality Press. 
Caridi, M., Crippa, L., Perego, A., Sianesi, A., \& Tumino, A. (2010). Measuring visibility to improve supply chain performance: a quantitative approach. Benchmarking, 17(4), 593-615. http://dx.doi.org/10.1108/14635771011060602.

Chan, F. T. S. (2003). Performance measurement in a supply chain. International Journal of Advanced Manufacturing Technology, 21(7), 534-548. http://dx.doi.org/10.1007/s001700300063.

Childerhouse, P., Disney, S. M., \& Towill, D. R. (2008). On the impact of order volatility in the European automotive sector. International Journal of Production Economics, 114(1), 2-13. http://dx.doi.org/10.1016/j.ijpe.2007.09.008.

Christopher, M., \& Holweg, M. (2011). "Supply chain 2.0": managing supply chains in the era of turbulence. International Journal of Physical Distribution \& Logistics Management, 41(1), 63-82. http://dx.doi.org/10.1108/09600031111101439.

Christopher, M., \& Holweg, M. (2017). Supply chain 2.0 revisited: a framework for managing volatility-induced risk in the supply chain. International Journal of Physical Distribution \& Logistics Management, 47(1), 2-17. http://dx.doi.org/10.1108/1JPDLM-09-2016-0245.

Dattakumar, R., \& Jagadeesh, R. (2003). A review of literature on benchmarking. Benchmarking, 10(3), 176-209. http://dx.doi. org/10.1108/14635770310477744.

Estampe, D., Lamouri, S., Paris, J.-L., \& Brahim-Djelloul, S. (2013). A framework for analysing supply chain performance evaluation models. International Journal of Production Economics, 142(2), 247-258. http://dx.doi.org/10.1016/j.jpe.2010.11.024.

Forrester, J. W. (1958). Industrial dynamics: a major breakthrough for decision makers. Harvard Business Review, 36(4), 37-66.

Germain, R., Claycomb, C., \& Dröge, C. (2008). Supply chain variability, organizational structure, and performance: the moderating effect of demand unpredictability. Journal of Operations Management, 26(5), 557-570. http://dx.doi.org/10.1016/j.jom.2007.10.002.

Gunasekaran, A., Patel, C., \& Tirtiroglu, E. (2001). Performance measures and metrics in a supply chain environment. International Journal of Operations \& Production Management, 21(1/2), 71-87. http://dx.doi.org/10.1108/01443570110358468.

Handfield, R. B., Straube, F., Pfohl, H.-C., \& Wieland, A. (2013). Trends and strategies in logistics and supply chain management: embracing global logistics complexity to drive market advantage. Hamburg: DVV Media Group.

Hyndman, R. J., \& Koehler, A. B. (2006). Another look at measures of forecast accuracy. International Journal of Forecasting, 22(4), 679-688. http://dx.doi.org/10.1016/j.jforecast.2006.03.001.

Johnson, M. E. (2001). Learning from toys: lessons in managing supply chain risk from the toy industry. California Management Review, 43(3), 106-124. http://dx.doi.org/10.2307/41166091.

Kerkkänen, A., Korpela, J., \& Huiskonen, J. (2009). Demand forecasting errors in industrial context: measurement and impacts. International Journal of Production Economics, 118(1), 43-48. http://dx.doi.org/10.1016/j.ijpe.2008.08.008.

Kim, 1., \& Springer, M. (2008). Measuring endogenous supply chain volatility: beyond the bullwhip effect. European Journal of Operational Research, 189(1), 172-193. http://dx.doi.org/10.1016/j.ejor.2007.05.012.

Lee, H. L. (2002). Aligning supply chain strategies with product uncertainties. California Management Review, 44(3), 105-119. http:// dx.doi.org/10.2307/41166135.

Lee, H. L., Padmanabhan, V., \& Whang, S. J. (1997). Information distortion in a supply chain: the bullwhip effect. Management Science, 43(4), 546-558. http://dx.doi.org/10.1287/mnsc.43.4.546.

Leiras, A., González-Calderón, C. A., Brito Junior, 1., Villa, S., \& Yoshizaki, H. T. (Eds.). (2019). Operations management for social good: 2018 poms international conference in Rio. Switzerland: Springer Nature.

Mentzer, J. T., \& Moon, M. A. (2005). Sales forecasting management: a demand management approach (2nd ed.). Thousand Oaks: Sage Publications.

Nienhaus, J., Ziegenbein, A., \& Schoensleben, P. (2006). How human behaviour amplifies the bullwhip effect: a study based on the beer distribution game online. Production Planning and Control, 17(6), 547-557. http://dx.doi.org/10.1080/09537280600866587.

Nitsche, B. (2018). Unravelling the complexity of supply chain volatility management. Logistics, 2(3), 14. http://dx.doi.org/10.3390/ logistics2030014.

Nitsche, B. (2019). Development of an assessment tool to control supply chain volatility. Berlin: Universitätsverlag der TU Berlin.

Nitsche, B., \& Durach, C. F. (2018). Much discussed, little conceptualized: supply chain volatility. International Journal of Physical Distribution \& Logistics Management, 48(8), 866-886. http://dx.doi.org/10.1108/IJPDLM-02-2017-0078.

Nyoman Pujawan, 1. (2004). The effect of lot sizing rules on order variability. European Journal of Operational Research, 159(3), 617635. http://dx.doi.org/10.1016/S0377-2217(03)00419-3.

Peng Wong, W., \& Yew Wong, K. (2008). A review on benchmarking of supply chain performance measures. Benchmarking, 15(1), 25-51. http://dx.doi.org/10.1108/14635770810854335.

Randall, T., \& Ulrich, K. (2001). Product variety, supply chain structure, and firm performance: analysis of the U.S. bicycle industry. Management Science, 47(12), 1588-1604. http://dx.doi.org/10.1287/mnsc.47.12.1588.10237.

Sangwan, K. S., \& Choudhary, K. (2018). Benchmarking manufacturing industries based on green practices. Benchmarking, 25(6), 1746-1761. http://dx.doi.org/10.1108/BlJ-12-2016-0192.

Shafiee, M., Hosseinzadeh Lotfi, F., \& Saleh, H. (2014). Supply chain performance evaluation with data envelopment analysis and balanced scorecard approach. Applied Mathematical Modelling, 38(21-22), 5092-5112. http://dx.doi.org/10.1016/j.apm.2014.03.023.

Simatupang, T. M., \& Sridharan, R. (2004). Benchmarking supply chain collaboration: an empirical study. Benchmarking, 11(5), 484503. http://dx.doi.org/10.1108/14635770410557717.

So, K. C., \& Zheng, X. (2003). Impact of supplier's lead time and forecast demand updating on retailer's order quantity variability in a two-level supply chain. International Journal of Production Economics, 86(2), 169-179. http://dx.doi.org/10.1016/S09255273(03)00050-1.

Stewart, G. (1995). Supply chain performance benchmarking study reveals keys to supply chain excellence. Logistics Information Management, 8(2), 38-44. http://dx.doi.org/10.1108/09576059510085000.

Supply Chain Council. (2008). SCOR ${ }^{\circledR}$ supply chain operations reference model. The Supply Chain Council. 
Taylor, D. H., \& Fearne, A. (2009). Demand management in fresh food value chains: a framework for analysis and improvement. Supply Chain Management, 14(5), 379-392. http://dx.doi.org/10.1108/13598540910980297.

Van der Vorst, J. G. A. J., Beulens, A. J. M., Wit, W., \& Beek, P. (1998). Supply chain management in food chains: Improving performance by reducing uncertainty. International Transactions in Operational Research, 5(6), 487-499. http://dx.doi.org/10.1016/S09696016(98)00049-5.

Wagner, S. M., Ullrich, K. K. R., \& Transchel, S. (2014). The game plan for aligning the organization. Business Horizons, 57(2), $189-201$. http://dx.doi.org/10.1016/j.bushor.2013.11.002.

Weller, M., \& Crone, S. F. (2012). Supply chain forecasting: best practices \& benchmarking study (Technical Report, No. 2012-11-01). Lancaster Centre For Forecasting. Retrieved in 2019, May 15, from https://www.lancaster.ac.uk/media/lancaster-university/contentassets/documents/lums/forecasting/practitionerpapers/Weller_Crone_Techical_Report_Supply_Chain_Forecasting_Best_Practices_ and_Benchmarking_Study.pdf

Wieland, A., Handfield, R. B., \& Durach, C. F. (2016). Mapping the landscape of future research themes in supply chain management. Journal of Business Logistics, 37(3), 205-212. http://dx.doi.org/10.1111/jbl.12131.

Wong, C. Y., \& Hvolby, H.-H. (2007). Coordinated responsiveness for volatile toy supply chains. Production Planning and Control, 18(5), 407-419. http://dx.doi.org/10.1080/09537280701425564.

Zsidisin, G. A., Melnyk, S. A., \& Ragatz, G. L. (2005). An institutional theory perspective of business continuity planning for purchasing and supply management. International Journal of Production Research, 43(16), 3401-3420. http://dx.doi.org/10.1080/00207540500095613. 